\title{
The characteristics of nivolumab-induced colitis: an evaluation of three cases and a literature review
}

Ryosuke Yamauchi ${ }^{1,2}$, Toshihiro Araki ${ }^{1,2}$, Keiichi Mitsuyama $^{1,2^{*}}$ (D), Takaaki Tokito ${ }^{3}$, Hidenobu Ishii ${ }^{3}$, Shinichiro Yoshioka ${ }^{1,2}$, Kotaro Kuwaki ${ }^{1,2}$, Atsushi Mori ${ }^{1,2}$, Tetsuhiro Yoshimura ${ }^{1,2}$, Osamu Tsuruta ${ }^{1}$ and Takuji Torimura ${ }^{1}$

\begin{abstract}
Background: The use of immune-checkpoint inhibitors in cancer treatment has become increasingly common, resulting in an increase in the incidence of related side effects. Diarrhoea and colitis have been previously documented as gastrointestinal tract-related side effects of immune-checkpoint inhibitors. Although PD-1/PD-L1 inhibitors produce fewer side effects than CTLA-4 inhibitors, diarrhoea and colitis continue to be reported. However, little is known about the endoscopic features associated with PD-1/PD-L1 inhibitors. In this report, we describe three cases of colitis induced by a PD-1 inhibitor nivolumab. These cases showed endoscopic findings characteristic of ulcerative colitis (UC). Treatment was in accordance with UC therapy, which resulted in beneficial outcomes.

Case presentation: Three patients with lung cancer treated with nivolumab presented with diarrhoea with (case 2) or without haematochezia (cases 1 and 3). Treatment with nivolumab was ceased and colonoscopy was performed, revealing endoscopic features similar to those of UC. These patients were diagnosed with nivolumab-induced colitis. Case 1 was treated with mesalazine, whereas cases 2 and 3 were treated with corticosteroids. Subsequently, their symptoms improved.
\end{abstract}

Conclusions: Nivolumab-induced colitis exhibited similar characteristics to UC. Treatment was similar to that for UC and was successful.

Keywords: Nivolumab, Immune-checkpoint inhibitor, Diarrhoea, Colitis, Ulcerative colitis

\section{Background}

Immune-checkpoint inhibitors, such as anti CTLA-4 antibody, anti PD-1 antibody, and anti PD-L1 antibody, have been shown to extend the survival rate of cancer patients [1-3], and their clinical usage has increased rapidly. These antibodies block the inhibitory signal by binding to the inhibitory receptor or its ligand and enhance the immune response against the tumour. However, blockade of immunity checkpoints is associated with inflammatory side effects known as immune-related adverse events. These events can affect any organ system but typically target the

\footnotetext{
* Correspondence: ibd@med.kurume-u.ac.jp

${ }^{1}$ Division of Gastroenterology, Department of Medicine, Kurume University

School of Medicine, 67 Asahi-machi, Kurume 830-0011, Japan

${ }^{2}$ Inflammatory Bowel Disease Center, Kurume University School of Medicine,

67 Asahi-machi, Kurume 830-0011, Japan

Full list of author information is available at the end of the article
}

gastrointestinal, hepatic, skin, and endocrine systems [4]. According to previous reports, there is a difference in the frequency of diarrhoea/colitis after blockade between CTLA-4 and PD-1/PD-L1. The incidence of Common Terminology Criteria for Adverse Events (CTCAE) grade $3 / 4$ diarrhoea is $1-2 \%$ among patients treated with PD- $1 /$ PD-L1 inhibitors compared to $3-6 \%$ among patients treated with CTLA-4 inhibitors. Grade 3/4 colitis accounts for $1-3 \%$ among patients treated with PD-1/PD-L1 inhibitors compared to 7-9\% among patients treated with CTLA-4 inhibitors. These findings suggest that colitis is less frequent during treatment with PD-1/PD-L1 inhibitors than during treatment with CTLA-4 inhibitors [3, 5, 6]. Moreover, little is known about the endoscopic features of PD-1/PD-L1 inhibitors except for what has been documented in the four case reports published to date [7-10].

(c) The Author(s). 2018 Open Access This article is distributed under the terms of the Creative Commons Attribution 4.0 International License (http://creativecommons.org/licenses/by/4.0/), which permits unrestricted use, distribution, and 
In this report, we describe three cases of anti-PD-1 antibody nivolumab cessation because of severe colitis and consider the clinical features of this condition.

\section{Case presentation}

As shown in Table 1, all three patients were adult men (case 1: 73, case 2: 78, case 3: 49 years old) with advanced non-small cell lung cancer at our hospital. Nivolumab was administered at a dose of $180 \mathrm{mg}$ every 2 weeks for cases 1 and 3 and 130 mg every 2 weeks for case 2. Symptoms have developed at different times in each case. Case 1 reported grade 3 diarrhoea 15 weeks after the administration. Case 2 reported grade 2 colitis and diarrhoea five times per day for 7 weeks after the administration. Case 3 reported grade 1 diarrhoea after 3 weeks which worsened to grade 2 over time. Symptoms did not improve after nivolumab cessation in these three cases and after administration of probiotics (cases 1 to 3 ) and antidiarrhoeal drugs (cases 1 and 2). In all cases, infectious diseases were excluded by stool culture.

They underwent endoscopy examination. Colonoscopic findings showed persistent inflammation of the entire colon in case 1 (Fig. 1a) and case 3 (Fig. 1c) and left-sided colon in case 2 (Fig. 1b) with a reddish, oedematous mucosa with increased mucous exudate and loss of vascularity (Fig. 1a-c). Histologically, mixed inflammatory infiltrates with crypt abscesses and cryptitis were observed in all cases (Fig. 1e-g). To clarify the similarity between their appearance, representative endoscopic and histological images of ulcerative colitis (UC) are presented in Fig. 1d and h.

As a result, they were diagnosed with nivolumab-induced colitis. Case 1 started treatment with $4000 \mathrm{mg}$ of mesalazine, and then the symptoms and colitis improved. The frequency of diarrhoea then decreased, and endoscopic examination indicated an improvement in the patient's condition. Cases 2 and 3 were treated with $2 \mathrm{mg} / \mathrm{kg} /$ day of methylprednisolone $(80 \mathrm{mg} /$ day for case $2,120 \mathrm{mg} /$ day for case 3 ). The diarrhoea and colitis gradually improved, prompting us to gradually reduce their corticosteroid treatment.

\section{Discussion and conclusions}

The PD-1 pathway controls autoimmunity and suppresses inflammation. Furthermore, inhibition of the PD-1 pathway in mice leads to various autoimmune diseases [11]. In a phase 1 study of nivolumab use in 296 patients, diarrhoea occurred in 33 patients, including three grade $3 / 4$ events [3]. In another study, the incidence rates of any grade or grade 3/4 diarrhoea in patients who had undergone treatment with nivolumab were 12.7 and $0.5 \%$, respectively. Furthermore, the incidence rates of colitis were 1.0 and $0.7 \%$, respectively [12]. The median time to onset of diarrhoea was 7 weeks in those who were treated with both ipilimumab and nivolumab [13].

The characteristic endoscopic findings of immunecheckpoint inhibitor-induced colitis have been reported previously. Inflammatory changes, such as exudates, granularity, loss of vascular pattern, and ulcerations extending from the rectum to parts or the entire colon, can be observed during colonoscopy in patients treated with ipilimumab [14]. These are similar to findings of inflammatory bowel disease, particularly UC (Fig. 1d). According to recent reports [7-10], similar findings were observed following treatment with nivolumab. We observed the same clinical findings, which included continuous mucosal inflammation, in the patients described in this study (Table 1). As such, the endoscopic images simulate UC to some extent but do not completely resemble it.

Tissue derived from patients with active colitis is histopathologically characterised by marked mixed inflammatory cell infiltrates in the lamina propria, including neutrophils, lymphocytes, plasma cells, and eosinophils [14]. Foci of neutrophilic cryptitis, crypt abscesses, glandular destruction, and erosions of the mucosal surface can be found with occasional ulcers $[15,16]$. According to the European Crohn's and Colitis Organisation guidelines, microscopic diagnosis of $\mathrm{UC}$ is based on widespread crypt architectural distortion and a diffuse transmucosal inflammatory infiltrate with basal plasmacytosis, which is eventually associated with an active component and results in cryptitis and crypt abscess [17]. As neither is a characteristic finding, it is difficult to differentiate based on pathological findings. However, Yanai et al. reported that prominent apoptosis in the colorectal epithelium appears to be a characteristic histological finding of nivolumab-induced colitis [10]. To clarify the differences between UC and nivolumab-induced colitis, further evidence derived from reported cases is needed.

As shown in this report, nivolumab-induced colitis was similar to UC in both colonoscopic and histological images. At present, the reason for the similarity is highly speculative since there was no report on the PD-1 pathway in UC. Nancey et al. analysed blood samples from patients for immune-checkpoint inhibitor-induced colitis by flow cytometry, revealing $\mathrm{T}$-cell imbalance including the decrease in regulatory T-cell and the increase in effector T-cells [18]. A similar T-cell imbalance was obtained from UC samples [19]. In PD-1-deficient mice, excessive cytokines are produced from $\mathrm{T}$ cells and are reported to cause autoimmune disease onset [20]. Together, excessive cytokine production from activated $\mathrm{T}$ cells may partly play an important role in the morphological and pathogenic similarity between the two diseases. 


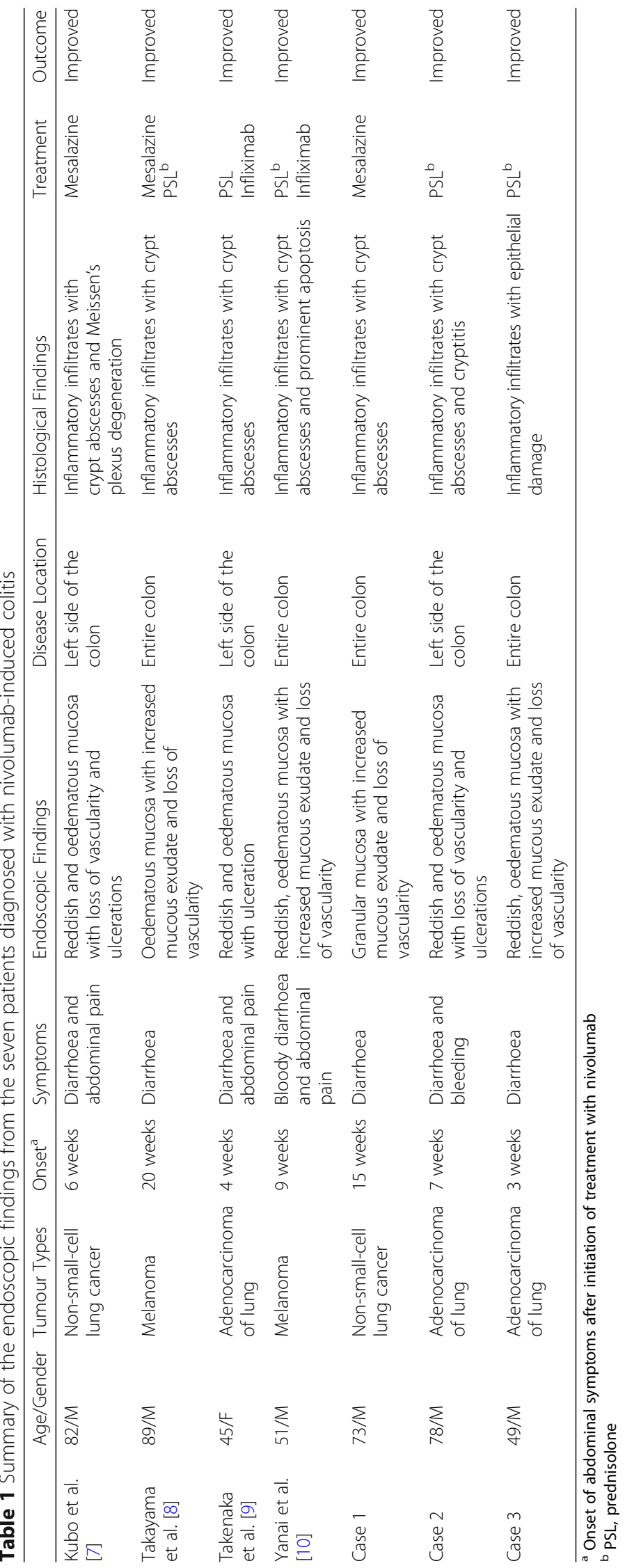



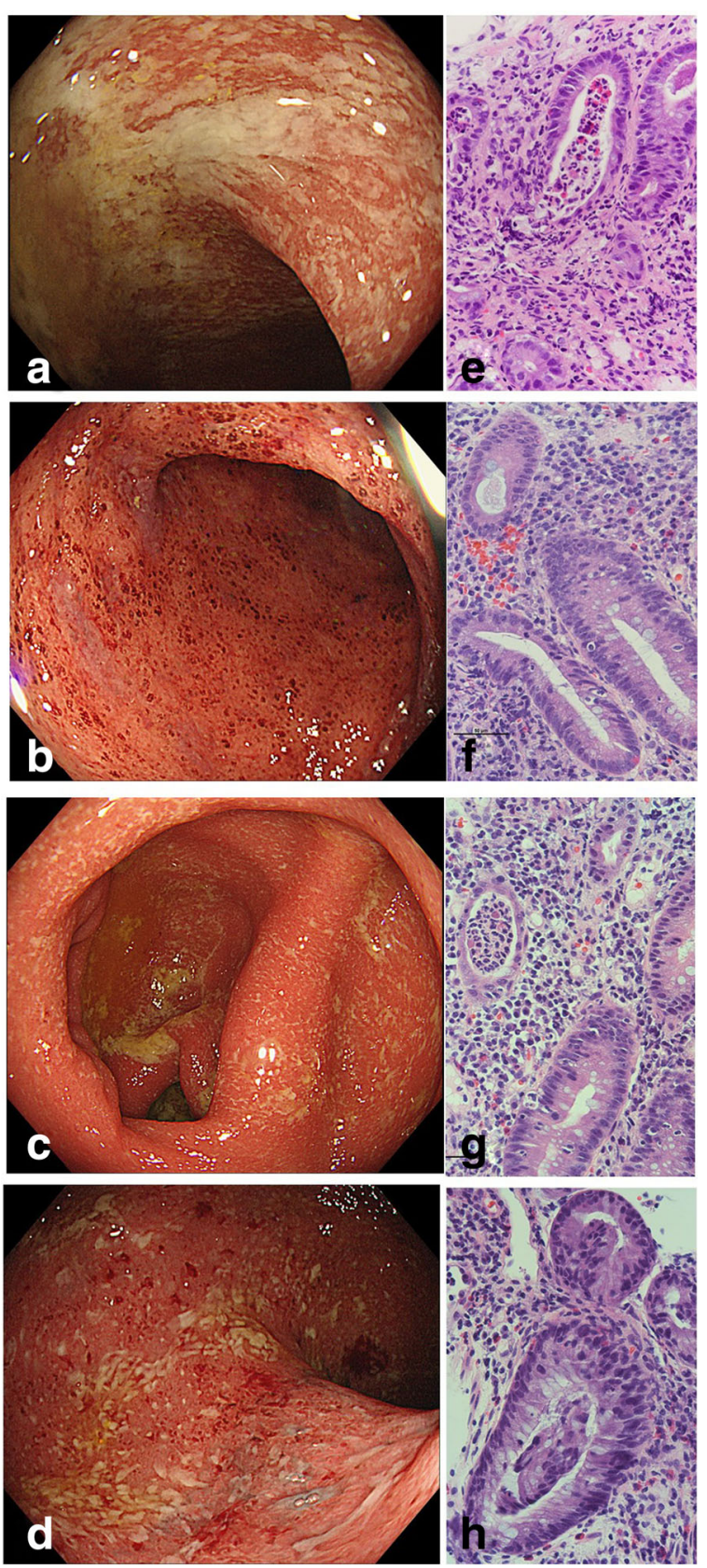

Fig. 1 Endoscopic and histopathologic findings. Case 1 (rectum, $\mathbf{a}$ and $\mathbf{e}$ ), 2 (sigmoid colon, $\mathbf{b}$ and $\mathbf{f}$ ), 3 (ascending colon, $\mathbf{c}$ and $\mathbf{g}$ ), and one patient with UC as a comparison (rectum, $\mathbf{d}$ and $\mathbf{h}$ ). $\mathbf{e}-\mathbf{h}$ stained with haematoxylin and eosin. Original magnification of microscopy, $\times 400$

If immune-related colitis is suspected, a gradual approach according to severity is recommended [21]. The National Cancer Institute's CTCAE has typically been used to define grades of diarrhoea and colitis during clinical treatment. According to previous reports [4, 13, 21, 22], if grade 1 diarrhoea/colitis is diagnosed, immune-checkpoint inhibitors should be administered continuously and symptomatic treatment and careful follow-up should be conducted. If the diarrhoea is of grade 2, where there is increased stool frequency, abdominal pain, mucous faeces, or bloody stool, immune-checkpoint inhibitors should be discontinued and symptomatic treatment should be performed. For grade 2 diarrhoea/colitis, oral administration of systemic corticosteroids (equivalent to $0.5-1 \mathrm{mg} / \mathrm{kg} /$ day methylprednisolone equivalent) for $>3$ days is recommended. If improvement is observed by systemic steroid administration, the steroid dose is gradually decreased over 48 weeks. Despite systemic corticosteroid administration, if improvement is not seen within 3-5 days or if the symptoms worsen, it should be treated as grade 3 . For grade 3 diarrhoea, intravenous administration of high-dose systemic steroids (1-2 $\mathrm{mg} / \mathrm{kg} / \mathrm{d}$ methylprednisolone equivalent) is recommended. In refractory cases, immune checkpoint inhibitors cannot be administered [22] and immunosuppressive treatment should be escalated. The potential risk of gastrointestinal perforation should be considered for patients in emergency situations. Infliximab therapy can be considered for patients who do not respond to steroids [10, 23] but cannot be used when gastrointestinal perforation or sepsis is observed.

Interestingly, mesalazine treatment was found to reduce the severity of immune-checkpoint inhibitor-induced colitis symptoms with an improvement in the frequency of diarrhoea and endoscopic findings [7, 8]. The same trend was observed in our patient who was treated with mesalazine, which functions as an inhibitor of inflammatory cytokines as well as prostaglandin-related substances $[24,25]$. In this way, mesalazine may improve patient outcomes following nivolumab-induced colitis. Together with the similar inhibitory action of steroids with mesalazine on cytokines [26, 27], the efficacy of mesalazine and steroids on this immune-related colitis may be induced at least in part through the inhibition of inflammatory cytokines.

As described in this series of cases, nivolumab-induced colitis exhibited similar characteristics as UC. Treatment was similar to that for UC and was largely successful.

\section{Abbreviations}

CTCAE: Common terminology criteria for adverse events; UC: Ulcerative colitis

\section{Acknowledgements}

We acknowledged to Dr. Atsushi Mizoguchi (Department of Immunology, Kurume University School of Medicine) for the helpful discussion about the mechanism of UC and PD-1-induced colitis.

Availability of data and materials

The datasets supporting the conclusions of this article are included within the article. 


\section{Authors' contributions}

RY and TA drafted the manuscript. KM critically revised the manuscript. TT1 and $\mathrm{HI}$ diagnosed the lung cancer and performed chemotherapy treatment. SY, KK, AM, and TY performed the endoscopic examination for these patients as a team. HY made substantial contributions in deciding the treatment strategy for this patient. OT made substantial contributions to the histopathological analysis of the resected specimen. $T 22$ revised this manuscript critically for important intellectual content and gave final approval of the version to be published. All authors read and approved the final manuscript.

\section{Authors' information}

$R Y, T A, K M, S Y, K K, A M, T Y, O T$, and $T T 2$ are gastroenterologist. TT1 and $H I$ are respiratory physician. All authors currently work in Japan.

\section{Ethics approval and consent to participate}

All procedures performed were in accordance with the ethical standards of the institutional and/or national research committee and with the 1964 Helsinki declaration and its later amendments or comparable ethical standards. This study was approved by the institutional review board of Kurume University Hospital (approval number: 2017-035).

\section{Consent for publication}

Written informed consent was obtained from all patients prior to the publication of this case report and any accompanying images.

\section{Competing interests}

The authors declare that they have no competing interests.

\section{Publisher's Note}

Springer Nature remains neutral with regard to jurisdictional claims in published maps and institutional affiliations.

\section{Author details}

'Division of Gastroenterology, Department of Medicine, Kurume University School of Medicine, 67 Asahi-machi, Kurume 830-0011, Japan. ${ }^{2}$ Inflammatory Bowel Disease Center, Kurume University School of Medicine, 67 Asahi-machi, Kurume 830-0011, Japan. ${ }^{3}$ Division of Respirology, Neurology, and Rheumatology, Department of Internal Medicine, Kurume University School of Medicine, 67 Asahi-machi, Kurume 830-0011, Japan.

Received: 25 May 2018 Accepted: 23 August 2018

Published online: 31 August 2018

\section{References}

1. Hodi FS, O'Day SJ, McDermott DF, Weber RW, Sosman JA, Haanen JB, et al Improved survival with ipilimumab in patients with metastatic melanoma. N Engl J Med. 2010;363:711-23.

2. Brahmer JR, Tykodi SS, Chow LQ, Hwu WJ, Topalian SL, Hwu P, et al. Safety and activity of anti-PD-L1 antibody in patients with advanced cancer. N Engl J Med. 2012;366:2455-65.

3. Topalian SL, Hodi FS, Brahmer JR, Gettinger SN, Smith DC, McDermott DF, et al. Safety, activity, and immune correlates of anti-PD-1 antibody in cancer. N Engl J Med. 2012;366:2443-54.

4. Postow MA. Managing immune checkpoint-blocking antibody side effects. Am Soc Clin Oncol Educ Book. 2015:76-83. https://doi.org/10.14694/ EdBook_AM.2015.35.76.

5. Hamid O, Robert C, Daud A, Hodi FS, Hwu WJ, Kefford R, et al. Safety and tumor responses with lambrolizumab (anti-PD-1) in melanoma. N Engl J Med. 2013;369:134-44.

6. Herbst RS, Soria JC, Kowanetz M, Fine GD, Hamid O, Gordon MS, et al. Predictive correlates of response to the anti-PD-L1 antibody MPDL3280A in cancer patients. Nature. 2014;515:563-7.

7. Kubo K, Kato M, Mabe K. Nivolumab-associated colitis mimicking ulcerative colitis. Clin Gastroenterol Hepatol. 2017;15:A35-6.

8. Takayama M, Ohara Y, Hata K, Kinoshita D, Okuda H, Kawasaki T, et al. A case of acute colitis mimicking ulcerative colitis during nivolumab infusion therapy for advanced melanoma. Gastrointest Endosc. 2017;59:450-5.

9. Takenaka T, Yamazaki K, Miura N, Harada N, Takeo S. Osimertinib reactivated immune-related colitis after treatment with anti-PD1 antibody for non-small cell lung cancer. Investig New Drugs. 2017;35:848-50.
10. Yanai S, Nakamura S, Matsumoto T. Nivolumab-induced colitis treated by infliximab. Clin Gastroenterol Hepatol. 2017;15:e80-1.

11. Okazaki T, Chikuma S, Iwai Y, Fagarasan S, Honjo T. A rheostat for immune responses: the unique properties of PD-1 and their advantages for clinical application. Nat Immunol. 2013;14:1212-8.

12. Weber JS, Hodi FS, Wolchok JD, Topalian SL, Schadendorf D, Larkin J, et al. Safety profile of nivolumab monotherapy: a pooled analysis of patients with advanced melanoma. J Clin Oncol. 2017;35:785-92.

13. Spain L, Diem S, Larkin J. Management of toxicities of immune checkpoint inhibitors. Cancer Treat Rev. 2016;44:51-60.

14. Gupta A, De Felice KM, Loftus EV, Khanna S. Systematic review: colitis associated with anti-CTLA-4 therapy. Aliment Pharmacol Ther. 2015;42:406-17.

15. Berman D, Parker SM, Siegel J, Chasalow SD, Weber J, Galbraith S, et al. Blockade of cytotoxic T-lymphocyte antigen-4 by ipilimumab results in dysregulation of gastrointestinal immunity in patients with advanced melanoma. Cancer Immun. 2010;10:11.

16. Garcia-Varona A, Odze RD, Makrauer F. Lymphocytic colitis secondary to ipilimumab treatment. Inflamm Bowel Dis. 2013;19:E15-6.

17. Magro F, Langner C, Driessen A, Ensari A, Geboes K, Mantzaris GJ, et al. European consensus on the histopathology of inflammatory bowel disease. J Crohns Colitis. 2013;7:827-51.

18. Nancey S, Boschetti G, Cotte E, Ruel K, Almeras T, Chauvenet M, et al. Blockade of cytotoxic T-lymphocyte antigen-4 by ipilimumab is associated with a profound long-lasting depletion of Foxp3+ regulatory T cells: a mechanistic explanation for ipilimumab-induced severe enterocolitis? Inflamm Bowel Dis. 2012:18:E1598-600.

19. Hanai H, lida T, Ikeya K, Abe J, Maruyama Y, Shimura T, et al. A new paradigm in ulcerative colitis: regulatory $T$ cells are key factor which induces/exacerbates UC through an immune imbalance. Mol Immunol. 2013:54:173-80.

20. Chikuma S, Terawaki S, Hayashi T, Nabeshima R, Yoshida T, Shibayama S, et al. PD-1-mediated suppression of IL-2 production induces CD8+ T cell anergy in vivo. J Immunol. 2009;182:6682-9.

21. Eigentler TK, Hassel JC, Berking C, Aberle J, Bachmann O, Grunwald V, et al. Diagnosis, monitoring and management of immune-related adverse drug reactions of anti-PD-1 antibody therapy. Cancer Treat Rev. 2016;45:7-18.

22. Weber JS, Kahler KC, Hauschild A. Management of immune-related adverse events and kinetics of response with ipilimumab. J Clin Oncol. 2012;30: 2691-7.

23. Marthey L, Mateus C, Mussini C, Nachury M, Nancey S, Grange F, et al. Cancer immunotherapy with anti-CTLA-4 monoclonal antibodies induces an inflammatory bowel disease. J Crohns Colitis. 2016;10:395-401.

24. Rousseaux C, Lefebvre B, Dubuquoy L, Lefebvre P, Romano O, Auwerx J, et al. Intestinal antiinflammatory effect of 5-aminosalicylic acid is dependent on peroxisome proliferator-activated receptor-gamma. J Exp Med. 2005;201: $1205-15$.

25. Ikeda I, Tomimoto A, Wada K, Fujisawa T, Fujita K, Yonemitsu K, et al. 5aminosalicylic acid given in the remission stage of colitis suppresses colitisassociated cancer in a mouse colitis model. Clin Cancer Res. 2007;13:6527-31.

26. Brack A, Rittner HL, Younge BR, Kaltschmidt C, Weyand CM, Goronzy JJ. Glucocorticoid-mediated repression of cytokine gene transcription in human arteritis-SCID chimeras. J Clin Invest. 1997;99:2842-50.

27. Hong SL, Levine L. Inhibition of arachidonic acid release from cells as the biochemical action of anti-inflammatory corticosteroids. Proc Natl Acad Sci U S A. 1976;73(5):1730-4.

\section{Ready to submit your research? Choose BMC and benefit from:}

- fast, convenient online submission

- thorough peer review by experienced researchers in your field

- rapid publication on acceptance

- support for research data, including large and complex data types

- gold Open Access which fosters wider collaboration and increased citations

- maximum visibility for your research: over 100M website views per year

At BMC, research is always in progress.

Learn more biomedcentral.com/submissions 